\title{
Retinoblastoma presentation, treatment and outcome in a large referral centre in Tehran: a 10-year retrospective analysis
}

\author{
Mohammad Faranoush $\mathbb{1}^{1,2} \cdot$ Narjes Mehrvar $\mathbb{D}^{1,3} \cdot$ Maryam Tashvighi ${ }^{1} \cdot$ Ido Didi Fabian $\mathbb{1}^{4}$ - Ofira Zloto ${ }^{5}$. \\ Covadonga Bascaran ${ }^{4}{ }^{4} \cdot$ Raheb Ghorbani $^{6} \cdot$ Fariba Ghasemi $^{7} \cdot$ Masood Naseripour $^{8} \cdot$ Ahad Sedaghat $^{8}$. \\ Mardawig Alebouyeh ${ }^{1} \cdot$ Azim Mehrvar ${ }^{1,9}$
}

Received: 2 October 2019 / Revised: 15 April 2020 / Accepted: 16 April 2020 / Published online: 4 May 2020

(c) The Author(s), under exclusive licence to The Royal College of Ophthalmologists 2020

\begin{abstract}
Background/objectives Early diagnosis, care and treatment of retinoblastoma is a challengeable issue for Iranian health system. This study was designed and conducted in a referral multidisciplinary centre in the capital city of Iran to evaluate management, care, prognosis and survival rates of paediatric patients with retinoblastoma.

Methods In this retrospective study, a total number of 309 patients younger than 15 years, diagnosed with retinoblastoma, who referred for diagnosis and treatment to MAHAK's Pediatric Cancer Treatment and Research Center (MPCTRC) from 2007 to 2017 were evaluated. All data were analyzed via SPSS version 22 software in regard of parametric and nonparametric data. Survival rates were analyzed using the Kaplan-Meyer method.

Results The mean age of patients was 20 months and the majority of patients (77\%) had leukocoria as a common clinical symptom at the time of diagnosis. Primary treatment methods were systemic chemotherapy (94\%), laser (35\%) and primary enucleation (28\%). Relapses occurred in nearly $42 \%$ of cases, and the median time from diagnosis to the first relapse was 9 months. At the time analyzing the data, $11 \%$ of patients died. Patients' 5 -year OS and RFS rates were $79.6 \%$ and $41.5 \%$, respectively.

Conclusion Comparing results with other conducted studies identifies that the recurrence rate was high in our considered patients. Also, OS and RFS rates in our study were not as considerable as other reports. Screening methods, updating protocols and follow-up of patients may lead to improvements in survival rates of patients with retinoblastoma.
\end{abstract}

\section{Introduction}

Retinoblastoma $(\mathrm{Rb})$ is the most common intraocular malignancy of childhood, accounting for up to $2 \%$ of all paediatric cancers $[1,2]$. The survival rates of this disease differs globally based on various factors, such as healthcare access [3]. Most $\mathrm{Rb}$ treatment and referral centres are related to middle and high-income countries so the 5-year survival of $\mathrm{Rb}$ in high-income countries is more than $95 \%$
Azim Mehrvar

drazimmehrvar@yahoo.com

1 MAHAK Hematology Oncology Research Center (MAHAKHORC), MAHAK Hospital, Tehran, Iran

2 Pediatric Growth and Development Research Center, Institute of Endocrinology and Metabolism, Iran University of Medical Sciences, Tehran, Iran

3 Cancer Research Center, Shahid Beheshti University of Medical Sciences, Tehran, Iran

4 International Centre for Eye Health, London School of Hygiene and Tropical Medicine, London, UK
5 SIREDO Oncology Center (Care, Innovation and Research for Children, Adolescents and Young Adults with Cancer), Institute Curie, Paris, France

6 Social Determinants of Health Research Center, Semnan University of Medical Sciences, Semnan, Iran

7 Farabi Eye Hospital, Shahid Beheshti University of Medical Sciences, Tehran, Iran

8 Eye Research Center, Rassoul Akram Hospital, Iran University of Medical Sciences, Tehran, Iran

9 AJA Cancer Epidemiology Research and Treatment Center (AJACERTC), AJA University of Medical Sciences, Tehran, Iran 
[4], while the 5-year survival of low-income countries is $\sim 30 \%[5,6]$.

Iran is classified as an upper-middle income country with a relatively large population of near 80 million [7]. The prognosis of $\mathrm{Rb}$ in Iranian paediatric patients was previously compared in different periods like 1991-2001 [4] and 2001-2007 [8] and in our study we evaluated this disease from 2007 to 2017.

In 2008, Abramson et al. reported ophthalmic artery chemotherapy for the first time as the treatment for $\mathrm{Rb}$ [9]. In 2012, Intravitreal chemotherapy for vitreous disease in $\mathrm{Rb}$ was reported by Munier et al. for the first time [10]. These novel modalities are recently used at the MAHAK's Pediatric Cancer Treatment and Research Center (MPCTRC), Tehran, an NGO multidisciplinary referral hospital for childhood malignancies. However, there is no data related to any change in prognosis rates of $\mathrm{Rb}$ after using these new treatment protocols in Iran. Therefore, the purpose of this study is to investigate the outcomes of $\mathrm{Rb}$ patients who referred to the MPCTRC from 2007 to 2017 .

\section{Materials and methods}

\section{Study design and population}

The medical records of all patients younger than 15 years who were diagnosed with $\mathrm{Rb}$ and treated at the MPCTRC from January 2007 to December 2017 were retrospectively reviewed. The sample size of this study was based on all of the patients who met the inclusion criteria during 2007-2017. Rb patients that refused treatment at MPCTRC, patients that diagnosed in MPCTRC and had been treated in other centres or patients that referred to MPCTRC only for second opinion were excluded from the study. The diagnosis of $\mathrm{Rb}$ was based on exam under anesthesia by an ophthalmologist in a referral ophthalmology centre. Afterwards, patients referred to MPCTRC for further therapeutic measurements. At the time of diagnosis, cerebrospinal fluid (CSF) and bone marrow involvement were checked for all patients. Considering CSF, proteins, glucose, red blood cells and white blood cells were examined for all samples.

\section{Data collection}

The following data were retrieved from medical case note records and documents of patients: age at presentation, signs/symptoms, laterality, number of lesions, disease group according to IIRC (International Intraocular Retinoblastoma Classification) [11], MRI findings and treatment modalities.
Recurrence was defined as the presence of vitreous seeds or micro seeding in the eyes after complete remission. Relapse time was defined as the time from diagnosis to the first recurrence of $\mathrm{Rb}$.

The final statuses of cases were categorized as follow: No evidence of disease, under treatment, loss to follow-up and death. Also, secondary malignancy as a long-term outcome was evaluated in the patients.

This case series was approved by the local institutional review board of the MPCTRC, and all patients and/or their parents provided informed consent for data gathering.

\section{Rb protocol at MPCTRC}

The main treatment modality for Rb cases at MPCTRC was intravenous chemotherapy (IVC) at the time of study. Also, primary enucleation was performed in eyes with stage $\mathrm{E}$ of disease at diagnosis. Moreover, secondary enucleation was performed in eyes with stage $\mathrm{D}$ of disease with no response to IVC. Table 1 shows chemotherapy regimens, agents and cycles which was administering at MPCTRC for patients with $\mathrm{Rb}$.

\section{Statistical analyses}

Quantitative variables were described as mean, range and standard deviation. Categorical variables were described as absolute and relative frequencies. Kaplan-Meier method analysis was conducted in order to estimated patients' 3-year and 5-year overall survival (OS; the time from diagnosis to the last visit of the patient) and 3-year relapse free survival (RFS; the time from diagnosis to the first event of relapse in the patient) rate. The Cox proportional hazards regression model was used to evaluate the effects of variables on OS and RFS. The overall significance level was set to an alpha of 0.05. The statistical analysis was carried out using SPSS software version 22.0 (SPSS, Inc., Chicago, IL, USA).

\section{Results}

\section{Demographics}

Between January 2007 and December 2017, a total number of 220 patients (309 eyes) with $\mathrm{Rb}$ referred to MPCTRC (115 males:105 females). The majority of patients $(n=194$, $87.3 \%$ ) were from Iran, and the remaining part of patients was referrals from nearby countries such as Iraq $(n=21)$, Afghanistan $(n=3)$ and Azerbaijan $(n=2)$. The mean age of patients at diagnosis was 20.9 months ( \pm 16.3 , range; 21 days to 61 months). Table 2 summarizes patients' demographic characteristics. 
Table 1 chemotherapy regimens for retinoblastoma at MPCTRC.

\begin{tabular}{|c|c|c|c|c|c|c|c|c|}
\hline \multirow{2}{*}{$\begin{array}{l}\text { Patients } \\
\text { Unilateral intra- } \\
\text { ocular group C } \\
\text { \& D }\end{array}$} & \multirow{2}{*}{$\begin{array}{l}\text { Protocol } \\
\text { High } \\
\text { dose VEC }\end{array}$} & \multicolumn{6}{|c|}{ Chemotherapy agents dose days per cycle } & \multirow{2}{*}{$\frac{\text { Cycles }}{8}$} \\
\hline & & $\begin{array}{l}\text { Vincristine } \\
1.5 \mathrm{mg} / \mathrm{m}^{2} \\
(1 \text { day } \\
\text { per cycle })\end{array}$ & $\begin{array}{l}\text { Carboplatin } \\
14 \mathrm{mg} / \mathrm{kg} \\
(2 \text { days per cycle })\end{array}$ & $\begin{array}{l}\text { Mannitol } 20 \% \\
7.5 \mathrm{cc} / \mathrm{kg} \\
(2 \text { days } \\
\text { per cycle })\end{array}$ & $\begin{array}{l}\text { Etoposide } \\
6 \mathrm{mg} / \mathrm{kg} \\
(2 \text { days } \\
\text { per cycle })\end{array}$ & - & - & \\
\hline $\begin{array}{l}\text { Unilateral intra- } \\
\text { ocular group B } \\
\text { \& C }\end{array}$ & VEC & $\begin{array}{l}\text { Vincristine } \\
1.5 \mathrm{mg} / \mathrm{m}^{2} \\
(1 \text { day } \\
\text { per cycle })\end{array}$ & $\begin{array}{l}\text { Carboplatin } \\
560 \mathrm{mg} / \mathrm{m}^{2} \\
(1 \text { day per cycle })\end{array}$ & $\begin{array}{l}\text { Mannitol } 20 \% \\
7.5 \mathrm{cc} / \mathrm{kg} \\
(1 \mathrm{day} \\
\text { per cycle })\end{array}$ & $\begin{array}{l}\text { Etoposide } \\
150 \mathrm{mg} / \mathrm{m}^{2} \\
(2 \text { days } \\
\text { per cycle })\end{array}$ & - & - & 8 \\
\hline $\begin{array}{l}\text { Unilateral intra- } \\
\text { ocular group B }\end{array}$ & $\mathrm{VC}$ & $\begin{array}{l}\text { Vincristine } \\
1.5 \mathrm{mg} / \mathrm{m}^{2} \\
(1 \text { day } \\
\text { per cycle })\end{array}$ & $\begin{array}{l}\text { Carboplatin } \\
560 \mathrm{mg} / \mathrm{m}^{2} \\
(1 \text { day per cycle })\end{array}$ & $\begin{array}{l}\text { Mannitol } 20 \% \\
7.5 \mathrm{cc} / \mathrm{kg} \\
\text { (one day } \\
\text { per cycle) }\end{array}$ & - & - & - & 8 \\
\hline $\begin{array}{l}\text { Bilateral intra- } \\
\text { ocular / } \\
\text { unilateral } \\
\text { relapse groups } \\
\text { C \& D }\end{array}$ & OPEC & $\begin{array}{l}\text { Vincristine } \\
1.5 \mathrm{mg} / \mathrm{m}^{2} \\
\text { (the } 1^{\mathrm{st}} \text { day } \\
\text { of } \\
\text { each cycle) }\end{array}$ & $\begin{array}{l}\text { Cyclophosphamide } \\
600 \mathrm{mg} / \mathrm{m}^{2} \\
\text { (the } 1 \mathrm{st} \text { day of } \\
\text { each cycle) }\end{array}$ & $\begin{array}{l}\text { Mesna } \\
400 \mathrm{mg} / \mathrm{m}^{2} \\
\text { (the } 1 \mathrm{st} \text { day of } \\
\text { each cycle) }\end{array}$ & $\begin{array}{l}\text { Cisplatin } \\
60 \mathrm{mg} / \mathrm{m}^{2} \\
\text { (the } 2 \mathrm{nd} \text { day } \\
\text { of } \\
\text { each cycle) }\end{array}$ & $\begin{array}{l}\text { Mannitol } 20 \% \\
7.5 \mathrm{cc} / \mathrm{kg} \\
\text { (the } 2 \mathrm{nd} \text { and } 3 \mathrm{rd} \\
\text { day of } \\
\text { each cycle) }\end{array}$ & $\begin{array}{l}\text { Etoposide } \\
100 \mathrm{mg} / \mathrm{m}^{2} \\
\text { (the } 4 \text { th day } \\
\text { of } \\
\text { each cycle) }\end{array}$ & 8 \\
\hline $\begin{array}{l}\text { Relapse } \\
\text { patients/patients } \\
\text { with extra retinal } \\
\text { metastasis }\end{array}$ & ICE & $\begin{array}{l}\text { Ifosfamide } \\
1800 \mathrm{mg} / \mathrm{m}^{2} \\
(5 \text { days } \\
\text { per cycle })\end{array}$ & $\begin{array}{l}\text { Carboplatin } \\
400 \mathrm{mg} / \mathrm{m}^{2} \\
(2 \text { days per cycle })\end{array}$ & $\begin{array}{l}\text { Mesna } \\
400 \mathrm{mg} / \mathrm{m}^{2} \\
(5 \text { days } \\
\text { per cycle })\end{array}$ & $\begin{array}{l}\text { Etoposide } \\
100 \mathrm{mg} / \mathrm{m}^{2} \\
(5 \text { days } \\
\text { per cycle })\end{array}$ & $\begin{array}{l}\text { Mannitol } 20 \% \\
7.5 \mathrm{cc} / \mathrm{kg} \\
(2 \text { days } \\
\text { per cycle })\end{array}$ & - & 8 \\
\hline
\end{tabular}

\section{Clinical presentation}

The most common signs of the disease were leukocoria (76.8\%) followed by strabismus $(16 \%)$. At the time of diagnosis, 131 patients $(59.6 \%)$ had unilateral type of disease and $89(40.4 \%)$ children had bilateral type of disease.

Amongst the 131 unilateral cases, the most frequent clinical classifications were group D $(37,28.2 \%)$ followed by group E $(34,26 \%)$. Twenty-two cases $(16.8 \%)$ were not clinical group recorded.

Amongst bilateral cases (89 patients, 178 eyes), the most frequent clinical classifications were group D (42 eyes, $23.6 \%$ ) followed by group E (39 eyes, 22\%). In addition, clinical groups for 30 eyes (16.9\%) were not identified and recorded in their medical documents.

Three children had metastases at the time of diagnosis with the following characteristics:

(1) A 3-year-old male child referred with leukocoria. At the time of diagnosis, he had both CSF and bonemarrow involvement. His disease was classified as the unilateral intra ocular, multifocal stage $\mathrm{D} \mathrm{Rb}$ with the left eye and optic nerve involvement. $\mathrm{He}$ also underwent laser therapy and enucleation of his eye. The treatment procedure of the child had been finished and he was alive without any problem at the time of preparing this manuscript.

(2) A 3-year-old male child with leukocoria had unilateral left eye and bone marrow involvement with intraocular spread. The stage of disease and focality of the eye were not identified. His treatment protocol included enucleation, he was alive without any problem at the time of preparing this manuscript.

(3) A 6-month-old male child referred with leukocoria and bone marrow involvement. His disease was classified as bilateral (extra-ocular right eye and intra-ocular left eye) with right eye optic nerve involvement, but the stage of the disease was unknown. Both eyes were multifocal. The treatment modalities for this patient included enucleation, radiotherapy and laser therapy. Unfortunately, he died during his treatment procedure.

\section{Primary treatment}

A number of 207 patients (94.1\%) were administered by systemic chemotherapy. Out of them, the number of patients who were treated by VEC, high dose VEC and OPEC protocols were 144, 35 and 28 individuals, respectively.

The eyes of 107 cases $(34.6 \%)$ were treated using laser therapy. A number of $86(27.8 \%)$ patients underwent primary enucleation, among whom 65 cases were unilateral disease cases and 21 cases were bilateral disease (one eye).

During treatment process, $35.4 \%$ of unilateral cases showed regression and $64.6 \%$ of them showed progression. In bilateral cases, $25.3 \%$ regressed with treatment and $74.7 \%$ progressed.

Tables 3, 4 summarize treatment modalities according to IIRC groups and laterality of eyes. 


\section{Second event}

In total, $92(41.8 \%)$ patients experienced relapse among whom 26 of them experienced the second relapse, 8 of them had the third relapse, and 3 cases had the fourth relapse. Table 4 shows the number of relapses based on the laterality, stage and eyes' involvement. Table 5 also shows the number of relapses according to the stage of $\mathrm{Rb}$. The median time from the time of diagnosis to the time of first relapse was 9 months (Range: 27 days to 12 years). In enroled patients, enucleation as a primary treatment was more frequent for group $\mathrm{E}$ than group $\mathrm{D}$, and the rate of relapse in group $\mathrm{D} \mathrm{Rb}$ was more frequent than that of group E Rb. Statistically, there was a significant correlation ( $p$ value: 0.003 ) between the increase in the rate of enucleation in higher stages and the decrease in the rate of experiencing relapse. The risk of relapse for stage $\mathrm{D}$ of $\mathrm{Rb}$ was 2.13 times higher than stage $\mathrm{E}$ $(\mathrm{RR}=2.13,95 \%$ CI: $1.08-4.21, p=0.029)$.

Out of considered patients, one child had secondary malignancy as a long-term outcome. She was a case of bilateral $\mathrm{Rb}$ who underwent enucleation for her left eye. Unfortunately, 9 months after finalizing her treatment, she had a last visit during which she was diagnosed with relapse and her therapy started again. Five years later after finalizing her treatment modalities for relapse, she developed osteosarcoma as a secondary malignancy. At the time of writing of this paper, she was alive and her therapy procedure had been finished for nearly 18 months.

\section{Prognosis}

The median time of follow-up for considered patients was 17 months ( \pm SD, range: 1 month to 19 years). The median time of RFS was 9 months (range 1 day to 12 years.). Table 6 shows 3-year, 5-year and 10-year OS and RFS rates in patients.

At the end of following up, 157 patients out of alive ones had no evidence of disease, 38 patients were still under treatment, and 25 children $(11.4 \%, 14$ patients with unilateral disease, 11 patients with bilateral disease) died. In addition, there was no patient with a loss to follow-up status.

Cox regression analysis showed significant correlation between the stage of disease and RFS. The probability of confronting death in patients with extra-ocular $\mathrm{Rb}$ was 4.3 times more than those with intra-ocular type $(\mathrm{RR}=4.30$, 95\% CI: $1.49-12.45, p=0.007)$.

\section{Discussion}

Since published reports regarding to the incidence, management and follow-up of Iranian patients with $\mathrm{Rb}$ are rare, 
Table 3 Treatment modalities by IIRC group.

\begin{tabular}{|c|c|c|c|c|c|c|c|c|}
\hline \multirow[t]{2}{*}{ Treatment modalities } & \multicolumn{8}{|c|}{ IIRC groups } \\
\hline & $\begin{array}{l}\text { A (8) } \\
n(\%)\end{array}$ & $\begin{array}{l}\text { B (40) } \\
n(\%)\end{array}$ & $\begin{array}{l}\mathrm{C}(47) \\
n(\%)\end{array}$ & $\begin{array}{l}\mathrm{D}(87) \\
n(\%)\end{array}$ & $\begin{array}{l}\mathrm{E}(73) \\
n(\%)\end{array}$ & $\begin{array}{l}\text { D-E (2) } \\
n(\%)\end{array}$ & $\begin{array}{l}\text { NR (52) } \\
n(\%)\end{array}$ & $\begin{array}{l}\text { Total (309) } \\
n(\%)\end{array}$ \\
\hline \multicolumn{9}{|l|}{ Primary treatment } \\
\hline Systemic chemotherapy & $8(100 \%)$ & $39(97.5 \%)$ & $45(95.7 \%)$ & $82(94.3 \%)$ & $73(100 \%)$ & $2(100 \%)$ & $48(92.3 \%)$ & $297(96.1 \%)$ \\
\hline Laser & $3(37.5 \%)$ & $12(30 \%)$ & $23(48.9 \%)$ & $40(46 \%)$ & $15(20.5 \%)$ & - & $14(26.9 \%)$ & $107(34.6 \%)$ \\
\hline IOC & - & - & $2(4.3 \%)$ & $8(9.2 \%)$ & $2(2.7 \%)$ & - & $3(5.8 \%)$ & $15(4.8 \%)$ \\
\hline Cryo & $2(25 \%)$ & $3(7.5 \%)$ & $8(17 \%)$ & $27(31 \%)$ & $6(8.2 \%)$ & - & $8(15.4 \%)$ & $54(17.5 \%)$ \\
\hline Enu & $1(12.5 \%)$ & $7(17.5 \%)$ & $11(23.4 \%)$ & $19(21.8 \%)$ & $31(42.5 \%)$ & - & $17(32.7 \%)$ & $86(27.8 \%)$ \\
\hline IAC & - & $1(2.5 \%)$ & $6(12.8 \%)$ & $9(10.3 \%)$ & $3(4.1 \%)$ & $1(50 \%)$ & $4(7.7 \%)$ & $24(7.8 \%)$ \\
\hline \multicolumn{9}{|c|}{ Secondary treatment after relapse } \\
\hline Systemic chemotherapy & - & $1(2.5 \%)$ & $2(4.3 \%)$ & $5(5.7 \%)$ & - & - & $4(7.7 \%)$ & $12(3.9 \%)$ \\
\hline Laser & - & $2(5 \%)$ & $1(2.1 \%)$ & $7(8 \%)$ & - & - & $2(3.8 \%)$ & $12(3.9 \%)$ \\
\hline IOC & $1(12.5 \%)$ & $2(5 \%)$ & $1(2.1 \%)$ & $3(3.4 \%)$ & $1(1.4 \%)$ & - & $1(1.9 \%)$ & $9(2.9 \%)$ \\
\hline Cryo & - & - & - & $3(3.4 \%)$ & $2(2.7 \%)$ & - & $2(3.8 \%)$ & $7(2.3 \%)$ \\
\hline Enu & - & $3(7.5 \%)$ & $2(4.3 \%)$ & $19(21.8 \%)$ & $2(2.7 \%)$ & - & $4(7.7 \%)$ & $30(9.7 \%)$ \\
\hline IAC & $1(12.5 \%)$ & - & - & $6(6.9 \%)$ & - & - & - & $7(2.3 \%)$ \\
\hline
\end{tabular}

$N R$ not recognized, IOC intra ocular chemotherapy, IAC intra-arterial chemotherapy, Enu enucleation.

conducting this study we aimed to evaluate the situation of management and follow-up of considered patients in an Iranian referral childhood's malignancy centre.

A total number of 309 eyes were evaluated and the majority of them were related to male children with the mean age of 20.9 months. Unilateral and intra-ocular cases were the commonest laterality and pattern. Also, multifocality was more frequent than uni-focality in these patients. Another study was conducted on 87 eyes of patients with $\mathrm{Rb}$ over a 10-year period, in which the mean age of patients was 15.6 months, and the majority of individuals were female [12]. Considering the presentations and characterizations of patients with $\mathrm{Rb}$ in North-West of Iran, the mean age of patients were 24 months and unilaterality was more evident [13].

All of the individuals at MPCTRC had systemic chemotherapy. VEC, high dose VEC and OPEC were the common administered chemotherapeutic protocols. Except systemic chemotherapy, the other treatment modalities were laser therapy, cryotherapy, intra-arterial chemotherapy (IAC) and radiotherapy. In addition, results showed that $50 \%$ of patients underwent enucleation. Less than a half of the patients had regressed to their malignancy after treatment modalities. Some review articles showed that the salvage rate after systemic chemotherapy and local consolidation for patients with stages $\mathrm{A}$ and $\mathrm{B} \mathrm{Rb}$ was 90 to $100 \%$, while it was nearly $47 \%$ for patients with the stage D $[14,15]$. Brennan et al. [16] evaluated ocular salvage in 27 bilateral intra-ocular $\mathrm{Rb}$ by topotecan-based regimen. Their results revealed that event-free survival of patients was $69.2 \%$. Finally, they concluded that topotecan in combination with vincristine, carboplatin as well as aggressive therapies were more useful and effective in advanced $\mathrm{Rb}$ [16]. Modern treatment modalities gives advanced stages opportunities to be better treated [14]. In several studies, there was a controversy over the effectiveness of intra-venous chemotherapy (IVC) and IAC as primary treatment. In this regard, a meta-analysis of 26 studies revealed that IAC had more effect than IVC because of the higher rates of OS [17]. In spite of IAC's benefits, there will be some mild or severe short-term complications that should be anticipated in patients. The mild side effects of IAC could be eyelid oedema, blepharoptosis, orbital congestion and maybe temporary dysmotility [18]. Shields et al. announced that severe short-term complications of IAC could be acute or chronic vascular insult, particularly to the ophthalmic, retinal, and choroidal vessels [18].

The rate of recurrence in this study was $37 \%$. Kaliki et al. reported that only $7.7 \%$ of patients (Four out of 52) experienced recurrence [19]. In this regard, two other studies conducted by Berry et al. reported that rate of recurrence in $\mathrm{Rb}$ patients was nearly $0.7 \%$ (One out of 139) and 9.6\% (Five out of 52) [14, 20]. Also, a literature review showed that there were two main studies about patients with $\mathrm{Rb}$, in which the rate of recurrence was nearly $53 \%[15,21]$. Other reports of recurrence in the considered patients were less than $30 \%$ [22-24].

The median times of patients' follow-up and RFS were 17 and 9 months, and the 5-year and 10-year OS in patients were $79.6 \%$ and $68.2 \%$, respectively. OS and RFS rates were higher in patients with left eye involvement. Patients with bilateral $\mathrm{Rb}$ and right eye involvement had higher OS 
Table 4 treatment modalities according to the laterality.

\begin{tabular}{|c|c|c|c|c|c|c|c|c|c|c|c|c|c|c|c|c|}
\hline \multirow[t]{2}{*}{ Laterality } & \multirow[t]{2}{*}{ Eye } & \multirow[t]{2}{*}{ Stage $(n)$} & \multirow[t]{2}{*}{ ONI $(n)$} & \multicolumn{2}{|c|}{$\begin{array}{l}\text { Spread } \\
\text { pattern }(n)\end{array}$} & \multicolumn{3}{|c|}{ Focality $(n)$} & \multicolumn{6}{|c|}{ Primary Treatment modalities (n) } & \multirow[t]{2}{*}{ Relapse $(n)$} & \multirow[t]{2}{*}{ Death $(n)$} \\
\hline & & & & In. O & Ex. O & $\mathrm{UF}$ & $\mathrm{MF}$ & NR & Laser & Cryo & IOC & IAC & Enu & XRT & & \\
\hline \multirow[t]{12}{*}{ Unilateral } & \multirow[t]{6}{*}{ Right eye (56) } & $\mathrm{B}(4)$ & - & 4 & 0 & 3 & 1 & 0 & 2 & 1 & - & 1 & 1 & - & 1 & 0 \\
\hline & & $\mathrm{C}(3)$ & 2 & 1 & 2 & 1 & 1 & 1 & 2 & - & 1 & - & 1 & - & 0 & 0 \\
\hline & & $\mathrm{D}(24)$ & 4 & 19 & 5 & 8 & 11 & 5 & 10 & 10 & 1 & 7 & 13 & 1 & 12 & 4 \\
\hline & & E (13) & 5 & 8 & 5 & 2 & 5 & 6 & 1 & 1 & 2 & - & 9 & - & 3 & 1 \\
\hline & & D-E (2) & 1 & 2 & 0 & 1 & 0 & 1 & - & - & - & 1 & - & - & 1 & 0 \\
\hline & & NR (10) & 2 & 8 & 2 & 1 & 7 & 2 & 2 & 1 & 1 & 3 & 5 & 1 & 5 & 2 \\
\hline & \multirow[t]{6}{*}{ Left eye (75) } & A (2) & 1 & 2 & 0 & 1 & 1 & 0 & 1 & 1 & - & 1 & 1 & - & 1 & 0 \\
\hline & & B (6) & 1 & 6 & 0 & 2 & 2 & 2 & 3 & - & - & - & 3 & - & 2 & 0 \\
\hline & & C (13) & 4 & 12 & 1 & 3 & 8 & 2 & 9 & 3 & 2 & 6 & 3 & 1 & 6 & 0 \\
\hline & & $\mathrm{D}(21)$ & 5 & 15 & 6 & 1 & 17 & 3 & 10 & 10 & 2 & 5 & 10 & - & 11 & 1 \\
\hline & & E (21) & 10 & 6 & 15 & 2 & 12 & 7 & 4 & 2 & - & 2 & 13 & - & 4 & 3 \\
\hline & & NR (12) & 1 & 11 & 1 & 1 & 5 & 6 & 3 & 2 & 2 & 2 & 6 & 1 & 7 & 3 \\
\hline \multirow[t]{12}{*}{ Bilateral } & \multirow[t]{6}{*}{ Right eye (89) } & A (1) & 1 & 1 & 0 & 0 & 1 & 0 & 1 & - & - & - & - & - & 1 & 0 \\
\hline & & B (12) & 1 & 12 & 0 & 1 & 4 & 7 & 6 & - & 1 & - & 3 & - & 6 & 3 \\
\hline & & C (16) & 1 & 15 & 1 & 4 & 8 & 4 & 9 & 2 & 1 & - & 2 & - & 5 & 0 \\
\hline & & D (24) & 3 & 20 & 4 & 7 & 11 & 6 & 13 & 8 & 3 & 3 & 10 & 1 & 14 & 4 \\
\hline & & E (22) & 7 & 8 & 14 & 5 & 7 & 10 & 3 & 2 & 2 & 1 & 9 & - & 5 & 0 \\
\hline & & NR (14) & 5 & 11 & 3 & 3 & 6 & 5 & 5 & 3 & - & - & 6 & 1 & 8 & 4 \\
\hline & \multirow[t]{6}{*}{ Left eye (89) } & A (5) & 1 & 5 & 0 & 2 & 0 & 3 & 1 & 1 & - & - & - & - & 3 & 0 \\
\hline & & B (18) & 5 & 18 & 0 & 5 & 7 & 6 & 6 & - & 1 & - & - & - & 6 & 0 \\
\hline & & C (15) & 3 & 14 & 1 & 4 & 6 & 5 & 9 & 5 & 1 & - & 3 & - & 5 & 1 \\
\hline & & D (18) & 1 & 15 & 3 & 4 & 10 & 4 & 8 & 5 & - & - & 4 & 1 & 10 & 2 \\
\hline & & E (17) & 2 & 9 & 8 & 3 & 5 & 9 & 5 & 2 & 1 & - & 9 & - & 7 & 4 \\
\hline & & NR (16) & 6 & 12 & 4 & 4 & 7 & 5 & 5 & 3 & 3 & - & 4 & - & 8 & 4 \\
\hline
\end{tabular}

$O N I$ optic nerve involvement, $I n$. $O$ intra ocular, $E x$. $O$ extra ocular; $U F$ uni-focality, $M F$ multi-focality, $N R$ not recognized, $I O C$ intra-ocular chemotherapy, IAC intra-arterial chemotherapy, Enu Enucleation.

Table 5 Frequency of $\mathrm{Rb}$ recurrence episodes in eyes by IIRC group.

\begin{tabular}{|c|c|c|c|c|c|}
\hline \multirow[b]{2}{*}{ Clinical group } & \multicolumn{5}{|c|}{ Recurrence episodes } \\
\hline & $n$ & $\begin{array}{l}\mathrm{R} 1 \\
n\end{array}$ & $\begin{array}{l}\mathrm{R} 2 \\
n\end{array}$ & $\begin{array}{l}\text { R3 } \\
n\end{array}$ & \\
\hline A & 8 & 5 & 3 & 0 & 0 \\
\hline $\mathrm{B}$ & 40 & 14 & 2 & 0 & 0 \\
\hline $\mathrm{C}$ & 47 & 13 & 5 & 2 & 1 \\
\hline $\mathrm{D}$ & 87 & 47 & 17 & 8 & 3 \\
\hline $\mathrm{E}$ & 73 & 17 & 4 & 1 & 1 \\
\hline D-E & 2 & 0 & 0 & 0 & 0 \\
\hline NR & 52 & 23 & 9 & 3 & 0 \\
\hline Total & 309 & 119 & 40 & 14 & 5 \\
\hline
\end{tabular}

$R 1$ first recurrence, $R 2$ second recurrence, $R 3$ third recurrence, $R 4$ fourth recurrence.

rates, but the former had lower RFS than the latter. Survival rates of this malignancy have become nearly $100 \%$ by enucleation and external beam radiotherapy in high-income countries $[25,26]$. Meantime of following up and OS in different studies were different; for instance, in a study by Thampai follow-up was 14.5 months and 5-year OS was $55 \%$ for considered patients [27]. Shields et al. conducted a study on patients with $\mathrm{Rb}$, in which the mean follow-up was 19 months and the patients' OS rate was $72.2 \%$ [28]. Munier et al. finalized a study with 105.3 months of patients' follow-up [21], in this regard with high duration follow-up a study conducted by Fabian et al. with 64.4 months ocular follow-up [29]. Five-year patients' OS was $83.3 \%$ in a study by Yousef et al. [30]. Another study by Fabian et al. on patients with group $\mathrm{D} \mathrm{Rb}$ revealed a median follow-up of 55 months, and the survival rate for the whole cohort study was 63\% [29].

Naseripour in a review article about survival disparity of $\mathrm{Rb}$ patients in developing countries showed that in Iran, the survival rate of paediatric patients had increased from $69 \%$ in 1991-2001 to $83 \%$ in 2001-2007, and reached to $88 \%$ in 2012 in Iranian referral ophthalmology centres [31]. Ghassemi et al. had a project on 100 eyes with $\mathrm{Rb}$ to evaluate the 
Table 6 Patients' overall survival (OS) and relapse free survival rates (RFS).

\begin{tabular}{lllllll}
\hline & $\begin{array}{l}\text { Total patients }\left(n=\begin{array}{l}\text { Patients with right eye } \\
\text { involvement } \\
(n=56)\end{array}\right. \\
\text { 220) }\end{array}$ & $\begin{array}{l}\text { Patients with left eye } \\
\text { involvement } \\
(n=75)\end{array}$ & $\begin{array}{l}\text { Patients with bilateral } \\
\text { eyes involvement } \\
(n=89)\end{array}$ & $\begin{array}{l}\text { Patients with } \\
\text { relapse } \\
(n=92)^{\mathrm{a}}\end{array}$ & $\begin{array}{l}\text { Patients } \\
\text { without } \\
\text { relapse } \\
(n=128)^{\mathrm{b}}\end{array}$ \\
\hline 3-year OS & $86.1 \pm 0.03 \%$ & $81.9 \pm 0.07 \%$ & $89.9 \pm 0.04 \%$ & $85.8 \pm 0.05 \%$ & $83.9 \pm 0.05 \%$ & $90.3 \pm 0.03 \%$ \\
5-year OS & $79.6 \pm 0.04 \%$ & $77.3 \pm 0.08 \% \%$ & $82.5 \pm 0.06 \%$ & $78.5 \pm 0.07 \%$ & $73.3 \pm 0.06 \%$ & $90.3 \pm 0.03 \%$ \\
10-year OS & $68.2 \pm 0.11 \%$ & $77.3 \pm 0.08 \%$ & $82.5 \pm 0.06 \%$ & $65.4 \pm 0.13 \%$ & $61.1 \pm 0.12 \%$ & $90.3 \pm 0.03 \%$ \\
3-year RFS & $48.7 \pm 0.04 \%$ & $45.2 \pm 0.09 \%$ & $55 \pm 0.07 \%$ & $45.5 \pm 0.07 \%$ & - & - \\
5-year RFS & $41.5 \pm 0.05 \%$ & $45.2 \pm 0.09 \%$ & $47.6 \pm 0.08 \%$ & $36.2 \pm 0.07 \%$ & - & - \\
10-year RFS & $23.1 \pm 0.1 \%$ & $45.2 \pm 0.09 \%$ & $47.6 \pm 0.08 \%$ & $13.6 \pm 0.1 \%$ & - & - \\
\hline
\end{tabular}

${ }^{a}$ Patients who conferred with relapse as a second event.

${ }^{b}$ Patients who did not confer with relapse.

regression patterns of treated patients. The results showed that nearly $40 \%$ of cases had relapses and there was a significant correlation between $\mathrm{Rb}$ recurrence and the location and size of the tumours. Moreover, they concluded that changing regression patterns in patients who were administered by systemic chemotherapy with focal adjuvant treatments relates to the location and size of tumours [32]. In another Iranian study on 24 patients in 2014 with the mean age at diagnosis of 20.2 months, nearly $58.3 \%$ of patients were unilateral. The majority of patients had stage D (75\%), and also $50 \%$ of patients experienced relapse [33]. Analysis of data in the current study was similar to those previous published in Iran.

Canturk et al. [34] published a systematic review about the effect of socioeconomic and health related factors on survival rates of patients with $\mathrm{Rb}$ in developing countries. In that study, 164 published papers with 14,800 patients from 48 countries had been considered. According to the results, the estimated survival rates for low-income countries, lower middle income countries and upper-middle income countries were $40 \%, 77 \%$ and $79 \%$, respectively. They considered Iran as a middle income country with $715 \mathrm{Rb}$. The survival rate of those patients was $77 \%$, and $6 \%$ of them had metastasis at the time of diagnosis [34]. All Data were related to patients with $\mathrm{Rb}$ over a 10-year period (1998-2008) in Iran. The current study showed $1.4 \%$ of metastasis at the time of diagnosis and survival rate of $79.6 \%$.

\section{Conclusion}

Comparison between our results and the other studies emphasizes that recurrence rate in current considered patients was the same as nearby countries and previous published reports from Iran but more than that of developed countries. In addition, OS and RFS rates of patients were as same as that of other reports from Iran and less than that of developed countries. The disparity of recurrence and survival in Iran could be because of parental delay in referring children to healthcare centres. Furthermore, rejecting treatment modalities such as enucleation by parents could cause an increase in the rate of relapse. The multidisciplinary and teamwork of physicians, however, could lead to improve the quality of treatment and to increase the rate of survival rates. An unneglectable fact is that in developing countries such as Iran, unfortunately, updating treatment protocols and preparing up-to-date chemotherapeutic agents is challengeable; therefore, the survival rates of patients with $\mathrm{Rb}$ may be lower than what is expected for this disease.

Public awareness about screening and referring to physicians at the onset of any symptom of $\mathrm{Rb}$ in Iran can be helpful for decreasing the mean age at diagnosis. Screening methods, updating protocols and follow-up of patients also could lead to improve OS and RFS rates of patients with $\mathrm{Rb}$. In our study, we also had some limitations. To be more precise, a few number of patients usually refer to these centres stage $\mathrm{A}$ of $\mathrm{Rb}$, and because of the absence of molecular genetic tests, abnormalities in patients are rarely evaluated. Our suggestion is future planning for multicenter studies which could imply more patients. Also, collaboration with genetic laboratories can be useful for evaluating hereditary or non-hereditary abnormalities in patients.

\section{Summary}

What was known before

- The incidence and survival rates of patients with retinoblastoma in Iran are rare.

\section{What this study adds}

- The survival rate, prognosis, care and management of patients with retinoblastoma in Iran. 
Acknowledgements Authors are thankful for their missed colleague, Dr Elham Olad, who gathered data of this study. God bless her. Also, authors appreciate Dr Khubbin Khoshnazar who entered data in SPSS.

\section{Compliance with ethical standards}

Conflict of interest The authors declare that they have no conflict of interest.

Publisher's note Springer Nature remains neutral with regard to jurisdictional claims in published maps and institutional affiliations.

\section{References}

1. Dome JSR-GC, Spunt SL, Santana VM. Chapter 95: Pediatric solid tumors. In: Niederhuber JE, Armitage JO, Doroshow JH, Kastan MB, Tepper JE, editors. Abeloff's clinical oncology. 5th ed. Philadelphia: Elsevier; 2014.

2. Hurwitz RL, Shields CL, Shields JA. Retinoblastoma. In: Pizzo PA, Poplack DG, editors. Principles and practice of pediatric oncology. Philadelphia: Lippincott Williams \& Wilkins; 2016.

3. Dimaras H, Corson TW, Cobrinik D, White A, Zhao J, Munier FL, et al. Retinoblastoma. Nat Rev Dis Prim. 2015;1:15021.

4. Naseripour M, Ghasemi FK, Bakhtiari P, Vosoughi P, Arian F. Retinoblastoma survival in Iran: 10 years experience of a referral center. Iranian Journal of Ophtalmology. 2009;21:17-24.

5. Nyawira G, Kahaki K, Kariuki-Wanyoike M, Survival among retinoblastoma patients at the Kenyatta National Hospital, Kenya. JOECSA. 2013;17:15-19.

6. Dean M, Bendfeldt G, Lou H, Giron V, Garrido C, Valverde P, et al. Increased incidence and disparity of diagnosis of retinoblastoma patients in Guatemala. Cancer Lett. 2014;351:59-63.

7. Group TWB. The World Bank 2019. https://data.worldbank.org/? locations $=$ XT-IR.

8. Naseripour $M$, Nazari $H$, Bakhtiari $P$, Modarres-zadeh $M$, Vosough P, Ausari M. Retinoblastoma in Iran: outcomes in terms of patients' survival and globe survival. $\mathrm{Br} \mathrm{J}$ Ophthalmol. 2009;93:28-32.

9. Abramson DH, Dunkel IJ, Brodie SE, Kim JW, Gobin YP. A phase I/II study of direct intraarterial (ophthalmic artery) chemotherapy with melphalan for intraocular retinoblastoma: initial results. Ophthalmology. 2008;115:1398-404. e1.

10. Munier FL, Gaillard M-C, Balmer A, Soliman S, Podilsky G, Moulin AP, et al. Intravitreal chemotherapy for vitreous disease in retinoblastoma revisited: from prohibition to conditional indications. Br J Ophthalmol. 2012;96:1078-83.

11. Linn AM. Intraocular retinoblastoma: the case for a new group classification. Ophthalmol Clin N Am. 2005;18:41-53. viii

12. Rowlands MA, Mondesire-Crump I, Levin A, Mauguen A, Francis JH, Dunkel IJ, et al. Total retinal detachments due to retinoblastoma: outcomes following intra-arterial chemotherapy/ ophthalmic artery chemosurgery. PloS ONE 2018;13:e0195395.

13. Nabie R, Taheri N, Fard AM, Fouladi RF. Characteristics and clinical presentations of pediatric retinoblastoma in North-western Iran. Int J Ophthalmol. 2012;5:510.

14. Berry JL, Kogachi K, Aziz HA, McGovern K, Zolfaghari E, Murphree AL, et al. Risk of metastasis and orbital recurrence in advanced retinoblastoma eyes treated with systemic chemoreduction versus primary enucleation. Pediatr Blood Cancer. 2017;64:e26270.

15. Berry JL, Jubran R, Kim JW, Wong K, Bababeygy SR, Almarzouki $\mathrm{H}$, et al. Long-term outcomes of Group D eyes in bilateral retinoblastoma patients treated with chemoreduction and low-dose IMRT salvage. Pediatr Blood Cancer. 2013;60:688-93.

16. Brennan RC, Qaddoumi I, Mao S, Wu J, Billups CA, Stewart CF, et al. Ocular salvage and vision preservation using a topotecanbased regimen for advanced intraocular retinoblastoma. J Clin Oncol. 2017;35:72-7.

17. Chen Q, Zhang B, Dong Y, Mo X, Zhang L, Huang W, et al. Comparison between intravenous chemotherapy and intra-arterial chemotherapy for retinoblastoma: a meta-analysis. BMC Cancer 2018;18:486.

18. Shields CL, Bianciotto CG, Jabbour P, Griffin GC, Ramasubramanian A, Rosenwasser R, et al. Intra-arterial chemotherapy for retinoblastoma: report No. 2, treatment complications. Arch Ophthalmol. 2011;129:1407-15.

19. Kaliki S, Shields CL, Shah SU, Eagle RC, Shields JA, Leahey A. Postenucleation adjuvant chemotherapy with vincristine, etoposide, and carboplatin for the treatment of high-risk retinoblastoma. Arch Ophthalmol. 2011;129:1422-7.

20. Berry JL, Shah S, Bechtold M, Zolfaghari E, Jubran R, Kim JW. Long-term outcomes of Group D retinoblastoma eyes during the intravitreal melphalan era. Pediatr Blood Cancer. 2017;64:e26696.

21. Munier FL, Mosimann P, Puccinelli F, Gaillard M-C, Stathopoulos $\mathrm{C}$, Houghton $\mathrm{S}$, et al. First-line intra-arterial versus intravenous chemotherapy in unilateral sporadic group D retinoblastoma: evidence of better visual outcomes, ocular survival and shorter time to success with intra-arterial delivery from retrospective review of 20 years of treatment. Br J Ophthalmol. 2017;101:1086-93.

22. Shields CL, Bianciotto CG, Jabbour P, Ramasubramanian A, Lally SE, Griffin GC, et al. Intra-arterial chemotherapy for retinoblastoma: report No. 1, control of retinal tumors, subretinal seeds, and vitreous seeds. Arch Ophthalmol. 2011;129:1399-406.

23. Chen M, Jiang H, Zhang J, Shen G, Jiang Y, Li H, et al. Outcome of intra-arterial chemotherapy for retinoblastoma and its influencing factors: a retrospective study. Acta Ophthalmol. 2017;95:613-8.

24. Tuncer S, Sencer S, Kebudi R, Tanyıldız B, Cebeci Z, Aydın K. Superselective intra-arterial chemotherapy in the primary management of advanced intra-ocular retinoblastoma: first 4-year experience from a single institution in Turkey. Acta Ophthalmol. 2016;94:e644-e51.

25. Shields CL, Shields JA. Retinoblastoma management: advances in enucleation, intravenous chemoreduction, and intra-arterial chemotherapy. Curr Opin Ophthalmol. 2010;21:203-12.

26. Friedman DL, Krailo M, Villaluna D, Gombos D, Langholz B, Jubran R, et al. Systemic neoadjuvant chemotherapy for group B intraocular retinoblastoma (ARET0331): a report from the Children's oncology group. Pediatr Blood Cancer. 2017;64:e26394.

27. Thampi S, Hetts SW, Cooke DL, Stewart PJ, Robbins E, Banerjee A, et al. Superselective intra-arterial melphalan therapy for newly diagnosed and refractory retinoblastoma: results from a single institution. Clin Ophthalmol. 2013;7:981.

28. Shields CL, Manjandavida FP, Lally SE, Pieretti G, Arepalli SA, Caywood EH, et al. Intra-arterial chemotherapy for retinoblastoma in 70 eyes: outcomes based on the international classification of retinoblastoma. Ophthalmology. 2014;121:1453-60.

29. Fabian ID, Stacey AW, Johnson KP, Onadim Z, Chowdhury T, Duncan C, et al. Primary intravenous chemotherapy for group D retinoblastoma: a 13-year retrospective analysis. Br J Ophthalmol. 2017;101:82-8.

30. Yousef YA, Nazzal RM, Khalil MB, Deebajah R, Mehyar M, Hajja S, et al. Management outcome (s) in eyes with retinoblastoma previously inadequately treated with systemic chemotherapy alone without focal therapy. Oman J Ophthalmol. 2017;10:70. 
31. Naseripour M. "Retinoblastoma survival disparity": the expanding horizon in developing countries. Saudi J Ophthalmol. 2012;26:157-61.

32. Ghassemi F, Rahmanikhah E, Roohipoor R, Karkhaneh R, Faegh A. Regression patterns in treated retinoblastoma with chemotherapy plus focal adjuvant therapy. Pediatr Blood Cancer. 2013;60:599-604.
33. Ghassemi F, Ghanaati H, Karkhaneh R, Boujabadi L, Tabatabaie SZ, Rajabi MT. Outcome of retinoblastoma following limited sessions of intra-arterial chemotherapy in Iran. Iran J Radiol. 2014;11:e16958.

34. Canturk S, Qaddoumi I, Khetan V, Ma Z, Furmanchuk A, Antoneli C, et al. Survival of retinoblastoma in less-developed countries impact of socioeconomic and health-related indicators. Br J Ophthalmol. 2010;94:1432-6. 